\title{
PCDH8 inhibits glioma cell proliferation by negatively regulating the AKT/GSK3//ק-catenin signaling pathway
}

\author{
ZHENKUN ZONG ${ }^{1}$, HUI PANG ${ }^{2}$, RUTONG YU $^{1}$ and YUNQI JIAO ${ }^{1}$ \\ ${ }^{1}$ Department of Neurosurgery, The Affiliated Hospital of Xuzhou Medical University, \\ Xuzhou, Jiangsu 221002; ${ }^{2}$ Department of Cardiovascular Medicine, Xuzhou Central Hospital, Xuzhou Clinical \\ School of Xuzhou Medical University, Affiliated Xuzhou Hospital of Medical College of Southeast University, \\ Xuzhou, Jiangsu 221009, P.R. China
}

Received April 2, 2016; Accepted February 27, 2017

DOI: $10.3892 / 01.2017 .6629$

\begin{abstract}
Protocadherin-8 (PCDH8), a member of the protocadherin superfamily of proteins, is frequently lost in numerous types of cancer. However, the role that PCDH8 serves in human glioma, and the molecular mechanisms underlying this, remain unclear. Data from the present study demonstrated that the expression levels of PCDH8 mRNA and protein were significantly decreased in human glioma tissue compared with normal brain tissue. This suggested that PCDH8 is associated with the development of glioma. Thus, the role of PCDH8 in glioma cell proliferation was investigated by silencing and overexpressing PCDH8 in U251 glioma cells. Overexpression of PCDH8 significantly inhibited glioma cell proliferation, while silencing of PCDH8 using small interfering RNA promoted glioma cell proliferation. Restoration of PCDH8 decreased phosphorylated (p)-Rac- $\alpha$ serine/threonine-protein kinase (AKT) [Threonine (T)308/Serine (S)473] and p-glycogen synthase kinase-3 $\beta$ (p-GSK3ß) (S9) protein expression, thereby reducing the level of $\beta$-catenin when compared with the control. By contrast, silencing of PCDH8 increased levels of p-AKT (T308/S473) and p-GSK3 $\beta$ (S9), thereby increasing the level of $\beta$-catenin. In conclusion, the results of the present study suggested that PCDH8 suppressed glioma cell proliferation, and that the loss of PCDH8 may stimulate the proto-oncogene $\mathrm{Wnt} / \beta$-catenin signaling pathway and therefore promote glioma cell proliferation.
\end{abstract}

\section{Introduction}

Malignant glioma is the most common form of brain cancer (1). Patients with malignant glioma are typically treated

Correspondence to: Dr Hui Pang, Department of Cardiovascular Medicine, Xuzhou Central Hospital, Xuzhou Clinical School of Xuzhou Medical University, Affiliated Xuzhou Hospital of Medical College of Southeast University, 199 South Jie-Fang Road, Xuzhou, Jiangsu 221009, P.R. China

E-mail: phui81@126.com

Key words: glioma, protocadherin-8, $\beta$-catenin, tumor suppressor with a combination of surgery, chemotherapy and radiation therapy (1-4); however, the median survival time is only 12-15 months (2). Therefore, an improved understanding of the molecular mechanisms underlying glioma pathogenesis is essential in order to identify novel molecular targets for the treatment of glioma.

Protocadherins (PCDHs) are classified into three subgroups: $\delta 1$ (PCDH1, 7, 9, 11 and 20), $\delta 2$ (PCDH8, 10, 12, 17, 18 and 19) and $\varepsilon(\mathrm{PCDH} 15,16,21$ and cadherin related family member 5) (5). PCDHs are predominantly expressed in the central nervous system during embryonic development and in adulthood (6-9). The loss of PCDH family proteins has been demonstrated to contribute to the development of various types of human cancer, including colon, liver, renal, prostate, breast, nasopharyngeal and lung cancer, and astrocytoma (10-17). The loss of PCDH is due to gene deletion, mutation or promoter methylation (13-15). Overexpression of PCDH family proteins can inhibit tumor cell migration, in addition to anchorage-dependent and anchorage-independent proliferation $(13-15,17)$, suggesting that PCDH family proteins function as tumor suppressors.

The human PCDH8 gene is located at 13q21.1 (18), a putative tumor suppressor gene-rich chromosome. The inactivation of the PCDH8 gene caused by promoter methylation has previously been reported in various types of human cancer (16,19-22). However, the biological functions and clinical significance of the PCDH8 protein in glioma remains unclear. In the present study, the expression of PCDH8 mRNA and protein was detected in glioma and normal brain tissues. PCDH8 expression was subsequently knocked down or overexpressed in U87 and U251 glioma cell lines in order to assess how PCDH8 alters tumor cell phenotype and gene expression in vitro.

\section{Materials and methods}

Antibodies. The anti-PCDH8 antibody was purchased from Abcam (ab55507; 1:2000; Cambridge, UK). Antibodies specific for Rac- $\alpha$ serine/threonine-protein kinase (AKT; \#4691; 1:1,000), phosphorylated (p)-AKT [Threonine (T)308; \#13038; 1:1,000), p-AKT [Serine (S)473; \#4060; 1:1,000], glycogen synthase kinase (GSK)-3 $\beta$ (\#9315; 1:1,000) 
p-GSK3 $\beta$ [(S9); \#9322; 1:500], $\beta$-catenin (\#8480; 1:1,000), p- $\beta$-catenin (\#4176; $1: 500)$ and $\beta$-actin $(\# 3700 ; 1: 4,000)$ were purchased from Cell Signaling Technology, Inc. (Danvers, MA, USA). The anti-FLAG antibody (F3165; 1:5,000) was from Sigma-Aldrich (Merck KGaA, Darmstadt, Germany).

Tissue samples. A total of 10 samples of human glioma tissue (surgical resection) and 4 samples of non-tumorous brain tissue (internal decompression in cerebral trauma) were collected from February 2015 to January 2016 at The Affiliated Hospital of Xuzhou Medical University (Xuzhou, China). Surgically removed tissues histologically diagnosed, and the remaining fresh tissues were immediately frozen in liquid nitrogen and stored at $-80^{\circ} \mathrm{C}$ until required. Written informed consent was obtained from all patients and the present study was approved by the Research Ethics Committee of the Affiliated Hospital of Xuzhou Medical University.

Cell culture. Human glioma cell lines U87 and U251 were purchased from the Type Culture Collection of the Chinese Academy of Sciences (Shanghai, China). The cells were cultured in Dulbecco's modified Eagle medium (Invitrogen; Thermo Fisher Scientific, Inc., Waltham, MA, USA) supplemented with $10 \%$ fetal bovine serum (Tiangen Biotech Co., Ltd., Beijing, China) in a humidified incubator with $5 \% \mathrm{CO}_{2}$ at $37^{\circ} \mathrm{C}$.

RNA extraction, complementary (c)DNA synthesis and reverse transcription-quantitative polymerase chain reaction $(R T-q P C R)$ analysis. RNA was extracted from the fresh frozen tissue specimens using TRIzol ${ }^{\circledR}$ reagent (Shenggong, Shanghai, China) and cDNA was synthesized using the M-MLV reverse transcription reagents (Roche Diagnostics, Basel, Switzerland) according to the manufacturer's protocol. PCR reactions were performed with $1 \mu \mathrm{l}$ template from each reaction using an ABI 7300 Real-Time PCR system (Applied Biosystems; Thermo Fisher Scientific, Inc.). The reaction components include: $100 \mathrm{mM} \mathrm{KCl}, 4 \mathrm{mM} \mathrm{MgCl} 2,400 \mu \mathrm{M}$ dNTP, $2.5 \mathrm{U}$ Taq DNA Polymerase (Roche Diagnostics), $0.4 \mu \mathrm{M}$ Primer, $1 \mathrm{xSYBR}^{\circledR}$ Green (Roche Diagnostics). The thermocycling conditions were: $5 \mathrm{~min}$ at $95^{\circ} \mathrm{C}$ for pre-denaturation, $30 \mathrm{sec}$ at $95^{\circ} \mathrm{C}$, $30 \mathrm{sec}$ at $55^{\circ} \mathrm{C}, 30 \mathrm{sec}$ at $72^{\circ} \mathrm{C}$, the three steps $\left(30 \mathrm{sec}\right.$ at $95^{\circ} \mathrm{C}$, $30 \mathrm{sec}$ at $55^{\circ} \mathrm{C}, 30 \mathrm{sec}$ at $72^{\circ} \mathrm{C}$ ) were repeated for 25 cycles and the final step was $5 \mathrm{~min}$ at $72^{\circ} \mathrm{C}$. The primers used for the amplification of PCDH8 and $\beta$-actin were as follows: PCDH8 forward, 5'-GCCCAACATGTTCGACGTGC-3'; and reverse, 5'-GGAGTGTCCTTTCCACACCG-3'; $\beta$-actin forward, 5'-CATGTACGTTGCTATCCAGGC-3'; and reverse, 5'-CGC TCGGTGAGGATCTTCATG-3'. The products were 256 and $195 \mathrm{bp}$ long, respectively. For each sample, the threshold cycle $(\mathrm{Ct})$ was determined and normalized to the average of the housekeeping gene $(\Delta \mathrm{Ct}=\mathrm{Ct}$ Unknown-Ct Housekeeping gene). The determination of gene transcript levels in each sample was determined using the $2^{-\Delta \Delta \mathrm{Cq}}$ method (23).

Transient transfection of the PCDH8 plasmid and small interfering (si)RNAs. Transfection of the PCDH8 plasmid and siRNAs was performed using Lipofectamine ${ }^{\circledR} 2000$ Transfection reagent (Invitrogen; Thermo Fisher Scientific, Inc.) according to the manufacturer's protocol. A FLAG-tagged
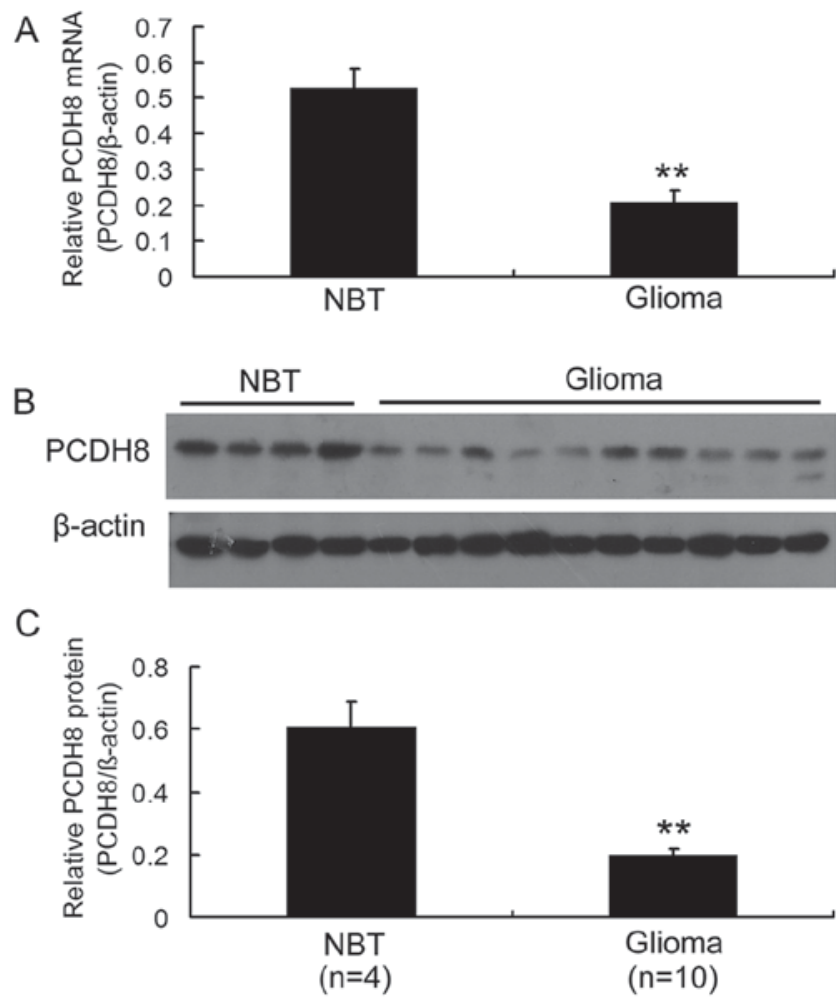

Figure 1. Expression of PCDH8 mRNA and protein in NBT and human glioma tissues. (A) Reverse transcription-quantitative polymerase chain reaction analysis of the mRNA levels of PCDH8. (B) Western blot analysis of the protein expression of PCDH8. (C) The statistical analysis of relative expression level of PCDH8 in non-tumorous brain tissues $(n=4)$ and glioma tissues $(n=10) .{ }^{* *} \mathrm{P}<0.01$ vs. the NBT group. PCDH8, protocadherin-8; NBT, normal brain tissue.

PCDH8 construct (3xFLAG-PCDH8) was purchased from Youbao Biotechnology Co., Ltd. (Changsha, China) for overexpression of PCDH8 in glioma cell, p3xFLAG-CMV-14 empty vector was used as a control. Three sets of siRNA duplexes that target human PCDH8 were obtained from Shanghai GenePharma Co., Ltd. (Shanghai, China). For silencing of PCDH8, three siRNA sequences were designed as follows: siPCDH8 \#1, 5'-GCCGUGUCCACUUAUGUCUTT-3'; siPCDH8 \#2, 5'-GCAGCUUCGACUAUGAGACTT-3'; and siPCDH8 \#3, 5'-GCUGAUCGUCAUCAUCGUGTT-3', non-targeting sequence: 5'-UUCUCCGAACGUGUCACGUTT-3' served as a negative control.

Western blotting. Total protein was extracted from tissues or U251/U87 cells using RIPA buffer $(50 \mathrm{mM}$ Tris- $\mathrm{HCl} \mathrm{pH} 7.4$, $150 \mathrm{Mm} \mathrm{NaCl}, 1 \%$ Triton X-100, $1 \%$ sodium deoxycholate, $0.1 \% \mathrm{SDS}, 1 \mathrm{mM}$ EDTA, and $1 \mu \mathrm{g} / \mathrm{ml}$ each aprotinin, leupeptin and pepstatin). Equal amounts of protein lysates $(80 \mu \mathrm{g})$ were run on $8 \%$ or $10 \%$ gels using SDS-PAGE and then transferred to $0.45-\mu \mathrm{m}$-pore-size polyvinylidene difluoride membranes (EMD Millipore, Billerica, MA, USA). Following blocking with $5 \%$ non-fat milk, the membranes were probed with primary antibodies (PCDH8, AKT, p-AKT(308), p-AKT(473), GSK $3 \beta, p-G S K 3 \beta$ and $\beta$-actin) at $4^{\circ} \mathrm{C}$ overnight and secondary antibodies (Goat Anti Mouse IgG-HRP; 1:5,000; Cat. AP124P; EMD Millipore; Goat Anti Rabbit IgG-HRP; 1:5,000, Cat. AP132P; EMD Millipore) at room temperature 
A

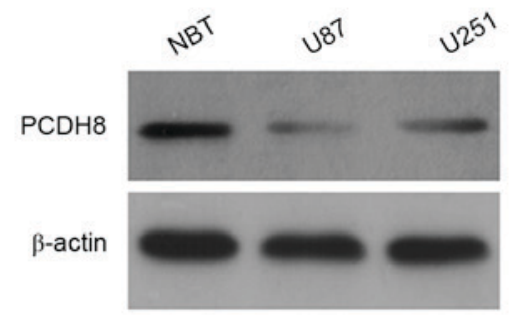

D

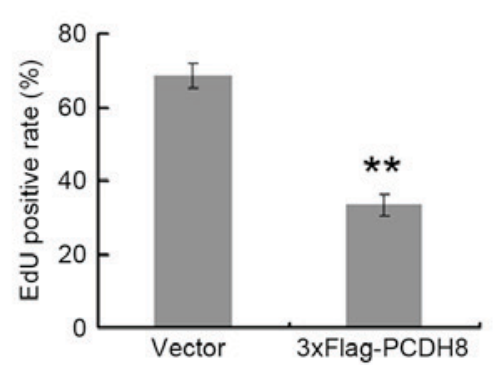

F

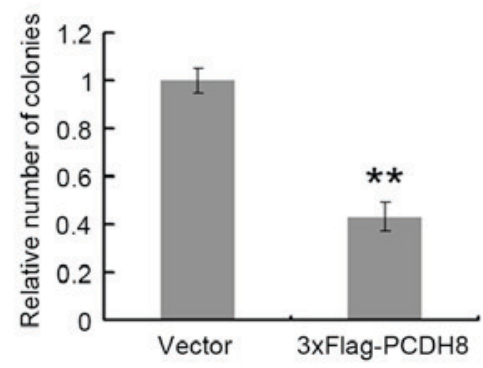

B

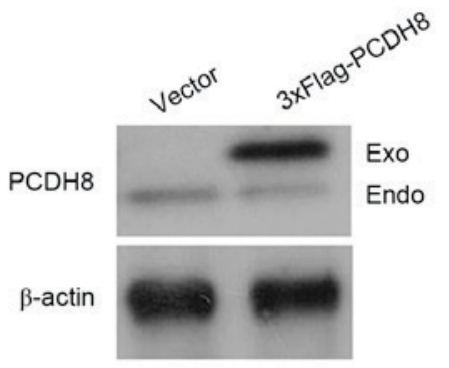

$E$

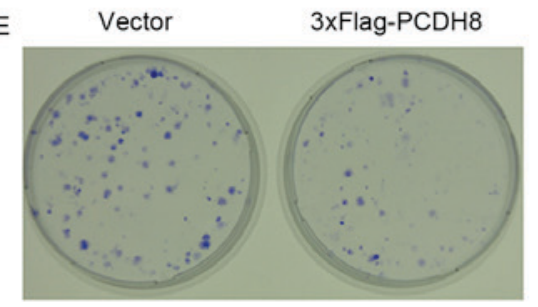

G

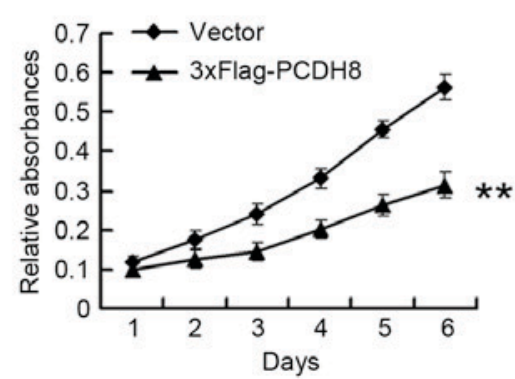

C

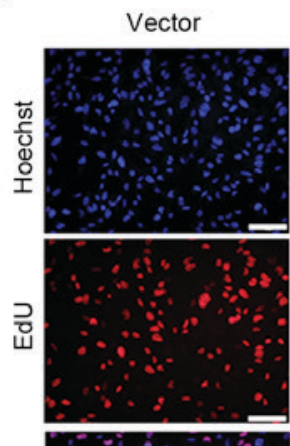
$3 \times$ Flag-PCDH 8

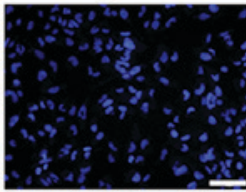

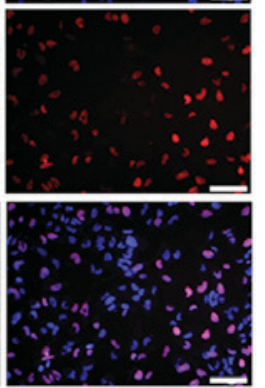

Figure 2. Restoration of PCDH8 expression inhibits glioma cell proliferation. (A) Western blot analysis of PCDH8 protein expression in NBT, and U87 and U251 cells. (B) Western blot of PCDH8 protein expression in U87 cells following transfection with FLAG-PCDH8. (C) Representative images and (D) quantification of the EdU incorporation assay performed in U87 cells following transfection with FLAG-PCDH8. (E) Representative images and (F) quantification of the colony formation assay performed in U87 cells transfected with FLAG-PCDH8. (G) MTT assay results. ** P<0.01 vs. the vector control group. PCDH8, protocadherin-8; NBT, normal brain tissue; Exo, exogenous; Endo, endogenous.

for $1 \mathrm{~h}$. Bound antibodies were detected using the Pierce ECL Plus Western Blotting substrate (Pierce; Thermo Fisher Scientific, Inc.) and exposed to X-ray films. Where band densities were quantified, ImageJ software (Version 2.1.4.7; National Institutes of Health, Bethesda, MD, USA) was used. The relative amounts of protein were determined by normalizing the densitometry value of the band of interest to that of the loading control $(\beta$-actin).

EdU incorporation cell proliferation assay. Cells were seeded into 96 -well plates at a density of $4 \times 10^{3}$ cells/well and incubated at $37^{\circ} \mathrm{C}$ for $24 \mathrm{~h}$ prior to exposure to $50 \mu \mathrm{M}$ EdU (Guangzhou RiboBio Co., Ltd., Guangzhou, China) for an additional $2 \mathrm{~h}$ at $37^{\circ} \mathrm{C}$. Cells were subsequently fixed with $4 \%$ paraformaldehyde for $20 \mathrm{~min}$ and treated with $0.5 \%$ Triton-X-100 for another $20 \mathrm{~min}$ at room temperature. The cells were washed 5 times with PBS, then $100 \mu 1$ 1X Apollo ${ }^{\circledR}$ Reaction Cocktail (Guangzhou RiboBio Co., Ltd.) was added to each well and the cells were incubated at room temperature for $30 \mathrm{~min}$. Cellular DNA was stained with $100 \mu \mathrm{l}$ of Hoechst $33342(5 \mu \mathrm{g} / \mathrm{ml})$ at room temperature for $20 \mathrm{~min}$ and visualized under a fluorescent microscope (IX71; Olympus Corporation, Tokyo, Japan).
MTT cell viability assay. A total of $2 \times 10^{3}$ cells in $200 \mu \mathrm{l}$ of culture medium were seeded into 96-well plates and culture. MTT (Sigma-Aldrich; Merck KGaA) was added into the medium to achieve a final concentration of $0.5 \mathrm{mg} / \mathrm{ml}$. Following incubation at $37^{\circ} \mathrm{C}$ for $4 \mathrm{~h}, 150 \mu \mathrm{l}$ of dimethyl sulfoxide was added to dissolve the crystals that had formed. Viable cells were counted every day by reading the absorbance at $490 \mathrm{~nm}$ using a Synergy ${ }^{\mathrm{TM}}$ Mx Multi-Mode Microplate Reader (BioTek Instruments, Inc., Winooski, VT, USA).

Colony formation assay. A total of 400 cells were seeded into a $6 \mathrm{~cm}$ dish and cultured for 10 days at $37^{\circ} \mathrm{C}$ prior to fixation with methanol and staining with $0.05 \%$ crystal violet to assess colony formation. The cells were washed with PBS and images of the plates were captured using a camera. Colonies containing $>50$ cells were counted.

Statistical analysis. All statistical analyses were performed using SPSS software (version 13.0; SPSS Inc., Chicago, IL, USA). Data were presented as the mean \pm standard error of the mean. Statistical significance was determined using a Student's t-test. $\mathrm{P}<0.05$ was considered to indicate a statistically significant difference. 
A

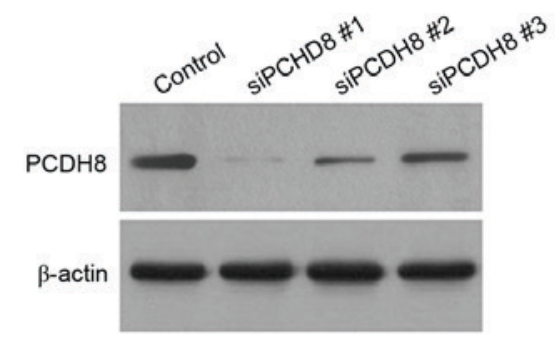

D
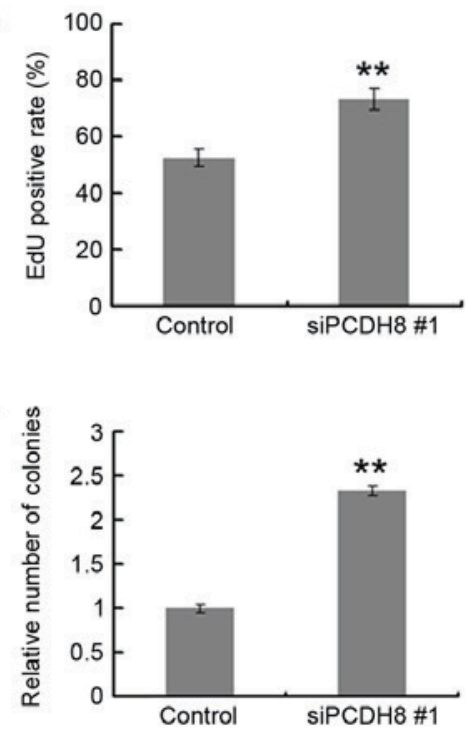

B

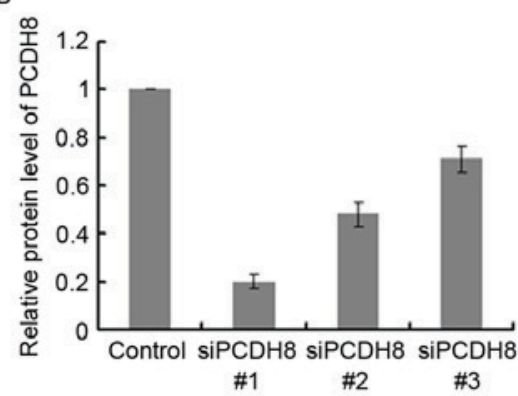

$\mathrm{E}$

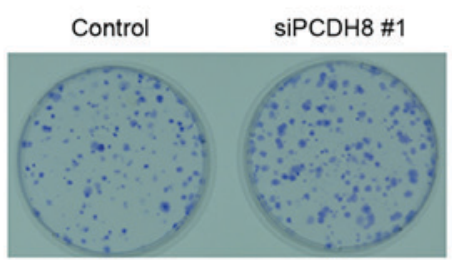

G

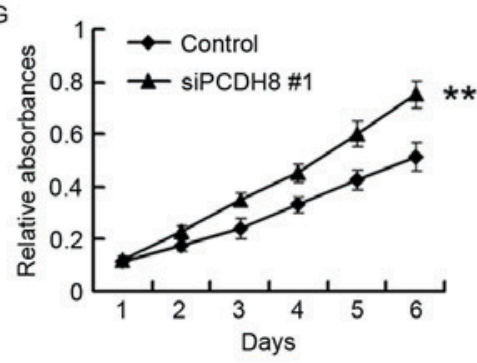

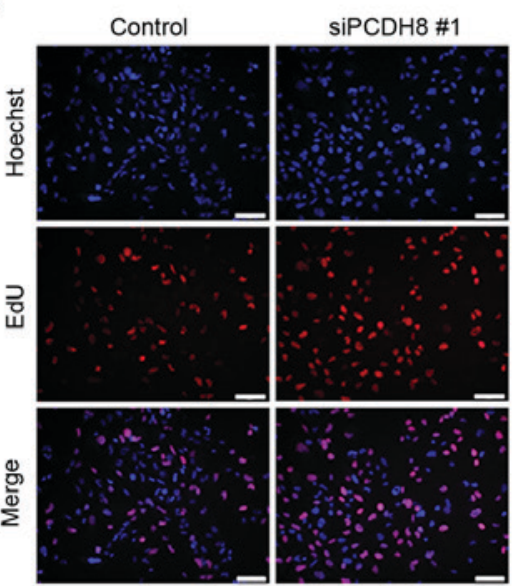

Figure 3. PCDH8 silencing promotes glioma cell proliferation. Western blot analysis (A) images and (B) quantification of siPCDH8 efficiency in U251 cells. (C) Representative images and (D) quantification of the EdU incorporation assay performed in U251 cells following transfection with siPCDH8. (E) Representative images and (F) quantification of the colony formation assay in U251 cells transfected with siPCDH8. (G) MTT assay results. ${ }^{* *} \mathrm{P}<0.01 \mathrm{vs}$. the control group. PCDH8, protocadherin-8; siPCDH8, small interfering RNA targeting PCDH8.

\section{Results}

Expression of PCDH8 in human glioma tissue and normal brain tissues. In order to investigate the expression of PCDH8 in human glioma, the mRNA and protein levels of PCDH8 in 10 samples of glioma tissue and 4 samples of normal brain tissue were examined. RT-qPCR analysis demonstrated that PCDH8 mRNA levels were significantly decreased in glioma tissue compared with normal brain tissue ( $\mathrm{P}<0.01$; Fig. 1A). In addition, western blot analysis revealed that $\mathrm{PCDH} 8$ protein levels were decreased in glioma tissue compared with normal brain tissue (Fig. 1B and $\mathrm{C} ; \mathrm{P}<0.01$ ). These data suggest that $\mathrm{PCDH} 8$ serves a role in gliomagenesis.

Restoration of PCDH8 inhibits the proliferation of human glioma cells. The expression of PCDH8 in U251 and U87 glioma cell lines was quantified by western blot analysis, using normal brain tissue as a control for PCDH8 expression. U251 and U87 cells expressed decreased levels of PCDH8 compared with that of normal brain tissue; however, PCDH8 expression in U251 cells was increased compared with that in U87 cells (Fig. 2A). U87 cells were transfected with a FLAG-tagged PCDH8 plasmid to restore PCDH8 expression (Fig. 2B) and the effect on cell proliferation was examined using an EdU incorporation assay (Fig. 2C and D). The EdU positive rate of the FLAG-tagged PCDH8 plasmid-transfected group was significantly decreased by $51.3 \%$ compared with the empty vector control group $(\mathrm{P}<0.01$; Fig. 2D). The colony formation ability (Fig. 2E) of U87 cells was also significantly reduced upon expression of FLAG-PCDH8 compared with the control group $(\mathrm{P}<0.01$; Fig. $2 \mathrm{~F})$. In addition, the MTT assay demonstrated that FLAG-PCDH8 expression significantly decreased the viability of U87 cells, compared with control group $(\mathrm{P}<0.01$; Fig. 2G).

PCDH8 silencing promotes the proliferation of human glioma cells. PCDH8 expression was downregulated using 3 PCDH8-specific siRNAs, using a control siRNA as the negative control. The siRNAs were screened for their efficacy in suppressing PCDH8 expression. The protein and mRNA silencing efficiency of siPCDH8 \#1 was $~ 80 \%$ in U251 cells (Fig. 3A and B); therefore, this siRNA was selected for use in further experiments. An EdU incorporation assay was performed in U251 cells to assess the effects of PCDH8 silencing on cell proliferation (Fig. 3C and D). The EdU positive rate of the siPCDH8 group was significantly increased by $133.3 \%$ compared with the control group $(\mathrm{P}<0.01$; Fig. $3 \mathrm{D})$. The colony formation ability of U251 cells (Fig. 3E) was also 
A

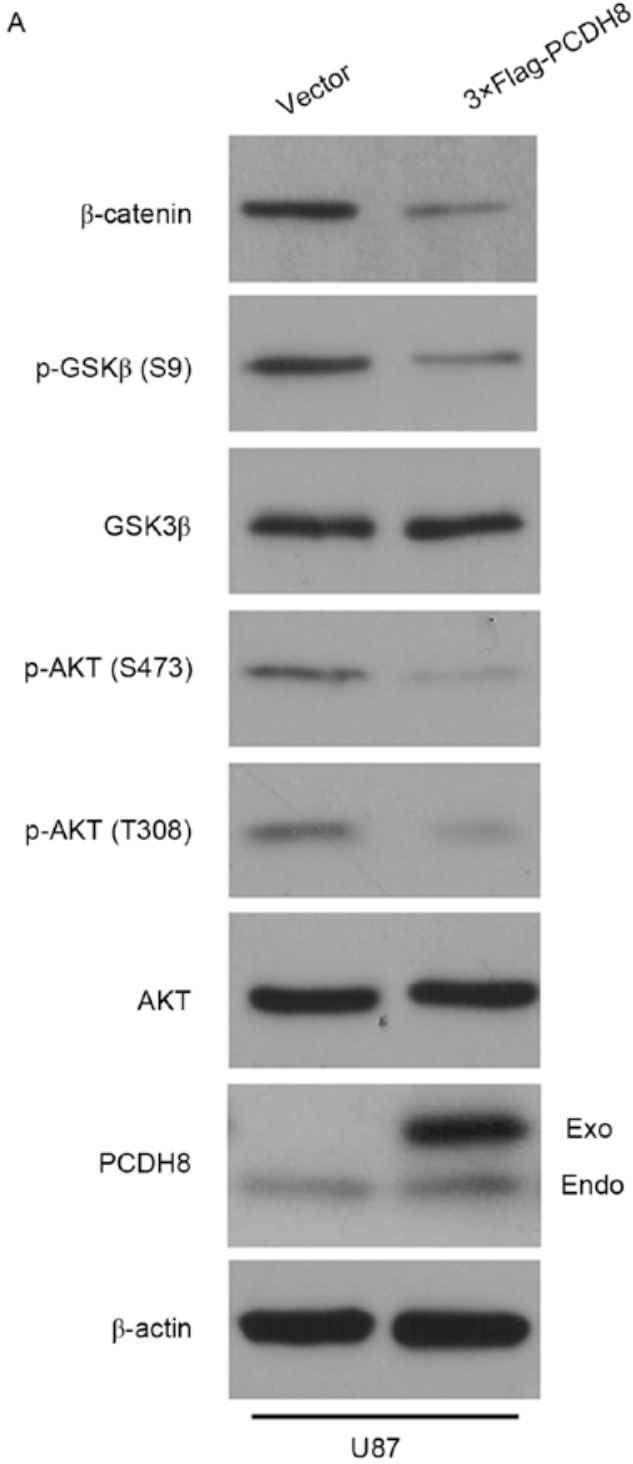

B

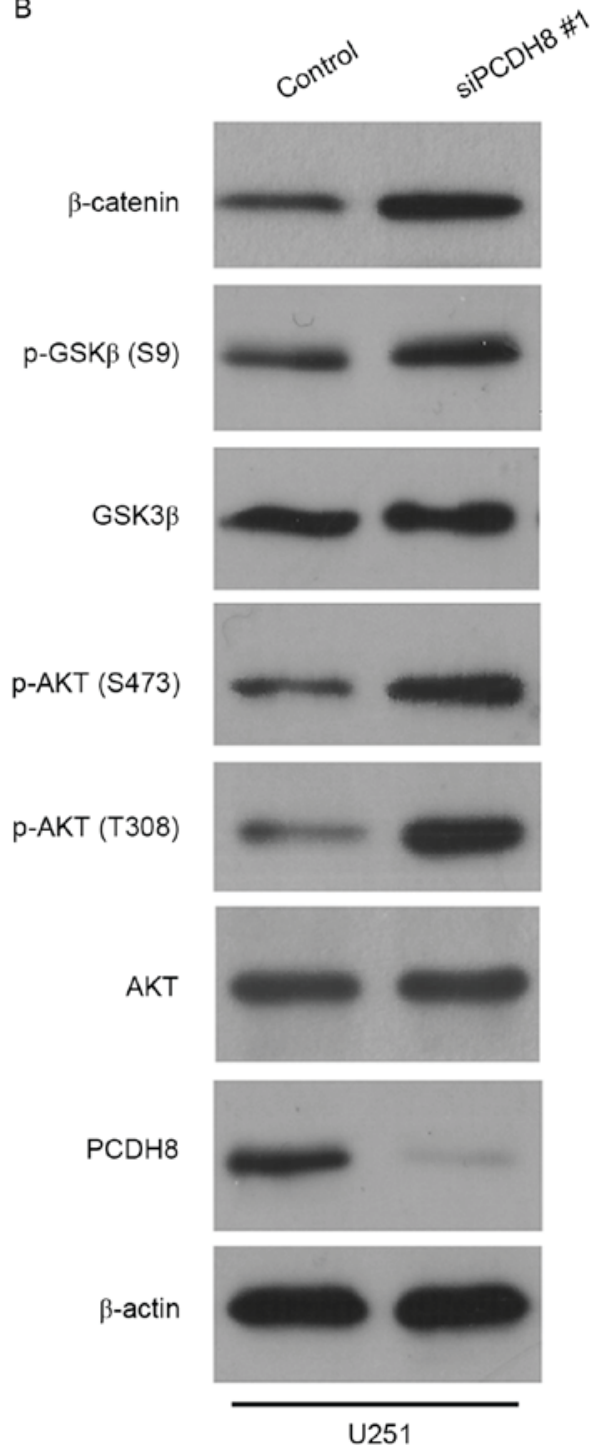

Figure 4. PCDH8 negatively regulates the AKT/GSK3 $\beta / \beta$-catenin signaling pathway. (A) Western blot analysis of p-AKT (T308), p-AKT (S473), p-GSK3 $\beta$ (S9) and $\beta$-catenin expression in U87 cells following transfection with FLAG-PCDH8. (B) Western blot analysis of p-AKT (T308), p-AKT (S473), p-GSK3 3 (S9) and $\beta$-catenin expression in U251 cells transfected with siPCDH8. PCDH8, protocadherin-8; AKT, Rac- $\alpha$ serine/threonine-protein kinase; p, phosphorylated; GSK3 $\beta$, glycogen synthase kinase-3 $\beta$; T, threonine; $\mathrm{S}$, serine; siPCDH8, small interfering RNA targeting PCDH8.

significantly increased upon silencing of PCDH8 $(\mathrm{P}<0.01$ vs. the control group; Fig. 3F). In addition, the MTT assay demonstrated that PCDH8 silencing significantly increased the growth of U251 cells compared with the control group $(\mathrm{P}<0.01$; Fig. 3G).

PCDH8 negatively regulates the AKT/GSK3 $\beta / \beta$-catenin signaling pathway. It has previously been reported that PCDH10, which belongs to the same subfamily of proteins as $\mathrm{PCDH} 8$, can inhibit tumor growth by regulating the AKT/GSK3 $\beta / \beta$-catenin signaling pathway (24); however, whether PCDH8 regulates this signaling pathway in human glioma cells remains unclear. To investigate this, the expression levels of AKT, p-AKT, GSK3 $\beta$, p-GSK3 $\beta$ and $\beta$-catenin were detected in U87 cells expressing FLAG-PCDH8 and U251 cells transfected with siPCDH8. Restoration of PCDH8 led to a marked decrease in p-AKT (T308/S473) and p-GSK3 $\beta$ (S9) expression, thereby reducing the level of $\beta$-catenin compared with the control group (Fig. 4A). Silencing of PCDH8 resulted in a notable increase in p-AKT (T308/S473) and p-GSK3 $\beta$ (S9) expression, which led to an increased level of $\beta$-catenin compared with the control group (Fig. 4B). These results suggest that PCDH8 inhibits glioma cell proliferation by negatively regulating the AKT/GSK $3 \beta / \beta$-catenin signaling pathway.

\section{Discussion}

Results from the present study demonstrated that PCDH8 mRNA and protein expression is decreased in glioma tissues compared with normal brain tissues. Restoration of PCDH8 expression in glioma cells significantly inhibited cell proliferation, while silencing of PCDH8 promoted cell proliferation. PCDH8 restoration decreased p-AKT (T308/S473) and $\mathrm{p}-\mathrm{GSK} 3 \beta$ (S9) expression, thereby reducing the expression of $\beta$-catenin, while silencing of PCDH8 resulted in a significant increase in p-AKT (T308/S473) and p-GSK3 $\beta$ (S9) 
expression, thereby elevating the level of $\beta$-catenin. Therefore, the loss of PCDH8 expression may contribute to glioma development. However, further studies are required to investigate the role that PCDH8 serves in glioma in vivo. Data from the present study indicates that the expression level of PCDH8 is important for the development of glioma; therefore, PCDH8 may be a potential biomarker for the early detection of or prognosis of glioma.

It has previously been reported that the PCDH8 gene is frequently methylated in the development of human cancer, which is correlated with poor survival rates $(7,14,18,22)$, indicating that PCDH8 functions as a tumor suppressor. Methylation is typically used to inactivate specific genes. Methylation of PCDH8 may inhibit the transcription of $\mathrm{PCDH}$, thereby contributing to the progression of cancer. The results from the present study demonstrated that the mRNA and protein levels of PCDH8 were decreased in human glioma tissue compared with normal brain tissue. The loss of PCDH8 mRNA and protein expression is consistent with previous reports on PCDH8 methylation in cancer (22).

The proto-oncogene $\mathrm{Wnt} / \beta$-catenin signaling pathways inhibit GSK3 $\beta$ activity through the promotion of AKT-mediated phosphorylation of GSK3 $\beta$ at S9. This subsequently promotes the accumulation of $\beta$-catenin, which translocates to the nucleus $(25,26)$. Data from the present study indicates that PCDH8 inhibits the activation of AKT. The subsequent reduction of GSK $3 \beta$ phosphorylation at S9 leads to the activation of GSK3 $\beta$, which in turn stimulates the degradation of $\beta$-catenin. These results indicate that PCDH8 serves a role in the regulation of the $\mathrm{Wnt} / \beta$-catenin signaling pathway through AKT. However, the specific molecular mechanism by which PCDH8 regulates AKT remains unclear. Further studies should focus on investigation of the downstream molecules directly regulated by PCDH8, which may further elucidate the molecular mechanism of PCDH8 regulated AKT signaling.

\section{Acknowledgements}

The present study was supported by the Xuzhou Municipal Science and Technology Bureau (Xuzhou, China; grant no. XZZD1020 and KC16SH042), Xuzhou Municipal Health and Family Planning Commission (Xuzhou, China; grant no. XWJ2011030) and Jiangsu Province's Young Provincial Talents Program (Jiangsu, China; grant no. QNRC2016383).

\section{References}

1. Meyer MA: Malignant gliomas in adults. N Engl J Med 359: 1850,2008

2. Buonerba C, Di Lorenzo G, Marinelli A, Federico P, Palmieri G, Imbimbo M, Conti P, Peluso G, De Placido S and Sampson JH: A comprehensive outlook on intracerebral therapy of malignant gliomas. Crit Rev Oncol Hematol 80: 54-68, 2011.

3. Sherman JH, Hoes K, Marcus J, Komotar RJ, Brennan CW and Gutin PH: Neurosurgery for brain tumors: Update on recent technical advances. Curr Neurol Neurosci Rep 11: 313-319, 2011.

4. Fiorentino A, Chiumento C, Caivano R, Cozzolino M, Pedicini P and Fusco V: Adjuvant radiochemotherapy in the elderly affected by glioblastoma: Single-institution experience and literature review. Radiol Med 118: 870-881, 2013 (In Italian).

5. Kim SY, Yasuda S, Tanaka H, Yamagata K and Kim H: Non-clustered protocadherin. Cell Adh Migr 5: 97-105, 2011.
6. Sano K, Tanihara H, Heimark RL, Obata S, Davidson M, St John T, Taketani S and Suzuki S: Protocadherins: A large family of cadherin-related molecules in central nervous system. EMBO J 12: 2249-2256, 1993.

7. Frank M and Kemler R: Protocadherins. Curr Opin Cell Biol 14: 557-562, 2002.

8. Phillips GR, Tanaka H, Frank M, Elste A, Fidler L, Benson DL and Colman DR: Gamma-protocadherins are targeted to subsets of synapses and intracellular organelles in neurons. J Neurosci 23: 5096-5104, 2003.

9. Kim SY, Chung HS, Sun W and Kim H: Spatiotemporal expression pattern of non-clustered protocadherin family members in the developing rat brain. Neuroscience 147: 996-1021, 2007.

10. Okazaki N, Takahashi N, Kojima S, Masuho Y and Koga H: Protocadherin LKC, a new candidate for a tumor suppressor of colon and liver cancers, its association with contact inhibition of cell proliferation. Carcinogenesis 23: 1139-1148, 2002.

11. Stassar MJ, Devitt G, Brosius M, Rinnab L, Prang J, Schradin T, Simon J, Petersen S, Kopp-Schneider A and Zöller M: Identification of human renal cell carcinoma associated genes by suppression subtractive hybridization. Br J Cancer 85: 1372-1382, 2001.

12. Chen MW, Vacherot F, De La Taille A, Gil-Diez-De-Medina S, Shen R, Friedman RA, Burchardt M, Chopin DK and Buttyan R: The emergence of protocadherin-PC expression during the acquisition of apoptosis-resistance by prostate cancer cells. Oncogene 21: 7861-7871, 2002.

13. Waha A, Güntner S, Huang TH, Yan PS, Arslan B, Pietsch T, Wiestler OD and Waha A: Epigenetic silencing of the protocadherin family member PCDH-gamma-A11 in astrocytomas. Neoplasia 7: 193-199, 2005.

14. Imoto I, Izumi H, Yokoi S, Hosoda H, Shibata T, Hosoda F, Ohki M, Hirohashi S and Inazawa J: Frequent silencing of the candidate tumor suppressor PCDH20 by epigenetic mechanism in non-small-cell lung cancers. Cancer Res 66: 4617-4626, 2006.

15. Ying J, Li H, Seng TJ, Langford C, Srivastava G, Tsao SW, Putti T, Murray P, Chan AT and Tao Q: Functional epigenetics identifies a protocadherin $\mathrm{PCDH} 10$ as a candidate tumor suppressor for nasopharyngeal, esophageal and multiple other carcinomas with frequent methylation. Oncogene 25: 1070-1080, 2006.

16. Yu JS, Koujak S, Nagase S, Li CM, Su T, Wang X, Keniry M, Memeo L, Rojtman A, Mansukhani M, et al: PCDH8, the human homolog of PAPC, is a candidate tumor suppressor of breast cancer. Oncogene 27: 4657-4665, 2008.

17. Yu J, Cheng YY, Tao Q, Cheung KF, Lam CN, Geng H, Tian LW, Wong YP, Tong JH, Ying JM, et al: Methylation of protocadherin 10 , a novel tumor suppressor, is associated with poor prognosis in patients with gastric cancer. Gastroenterology 136: 640-651. e1, 2009.

18. Strehl S, Glatt K, Liu QM, Glatt H and Lalande M: Characterization of two novel protocadherins (PCDH8 and PCDH9) localized on human chromosome 13 and mouse chromosome 14. Genomics 53: 81-89, 1998.

19. He D, Zeng Q, Ren G, Xiang T, Qian Y, Hu Q, Zhu J, Hong S and $\mathrm{Hu}$ G: Protocadherin8 is a functional tumor suppressor frequently inactivated by promoter methylation in nasopharyngeal carcinoma. Eur J Cancer Prev 21: 569-575, 2012.

20. Zhang D, Zhao W, Liao X, Bi T, Li H and Che X: Frequent silencing of protocadherin 8 by promoter methylation, a candidate tumor suppressor for human gastric cancer. Oncol Rep 28: 1785-1791, 2012.

21. Lin YL, Ma JH, Luo XL, Guan TY and Li ZG: Clinical significance of protocadherin-8 (PCDH8) promoter methylation in bladder cancer. J Int Med Res 41: 48-54, 2013.

22. Lin YL, Wang YL, Ma JG and Li WP: Clinical significance of protocadherin 8 (PCDH8) promoter methylation in non-muscle invasive bladder cancer. J Exp Clin Cancer Res 33: 68, 2014.

23. Livak KJ and Schmittgen TD: Analysis of relative gene expression data using real-time quantitative PCR and the 2(-Delta Delta C(T)) Method. Methods 25, 402-408, 2001.

24. Xu Y, Yang Z, Yuan H, Li Z, Li Y, Liu Q and Chen J: PCDH10 inhibits cell proliferation of multiple myeloma via the negative regulation of the Wnt/ $\beta$-catenin/BCL-9 signaling pathway. Oncol Rep 34: 747-754, 2015.

25. Ge X and Wang X: Role of Wnt canonical pathway in hematological malignancies. J Hematol Oncol 3: 33, 2010.

26. Liu YZ, Wu K, Huang J, Liu Y, Wang X, Meng ZJ, Yuan SX, Wang DX, Luo JY, Zuo GW, et al: The PTEN/PI3K/Akt and Wnt/ $\beta$-catenin signaling pathways are involved in the inhibitory effect of resveratrol on human colon cancer cell proliferation. Int J Oncol 45: 104-112, 2014. 